\title{
Outcome of pulmonary rehabilitation in COPD patients with severely impaired health status
}

\author{
This article was published in the following Dove Press journal: \\ International Journal of COPD \\ 30 November 201I \\ Number of times this article has been viewed
}

\author{
Dirk van Ranst ${ }^{1}$ \\ Henk Otten ${ }^{1,2}$ \\ Jan Willem Meijer' \\ Alex J van 't Hul',3 \\ 'Revant, Pulmonary Rehabilitation \\ Center 'Schoondonck', Breda, \\ ${ }^{2}$ Erasmus Medical Center, Department \\ of Pulmonary Diseases, Erasmus \\ University, Rotterdam, ${ }^{3} \mathrm{VU}$ Medical \\ Center, Department of Pulmonary \\ Diseases, VU University, Amsterdam, \\ The Netherlands
}

Introduction: Effects of pulmonary rehabilitation (PR) in chronic obstructive pulmonary disease (COPD) patients with severely impaired health status are poorly documented since these patients are usually excluded from clinical trials. This retrospective, observational study aims to study the impact of disease on health status and the effects of PR on COPD patients referred to a tertiary center for PR in The Netherlands.

Methods: Between June 2006 and June 2010, 437 patients with COPD were allocated to our intensive, comprehensive PR program. Patients participated in this interdisciplinary program for 12 weeks for a weekly average of 20-25 hours. Before and directly after, several measures of physical performance and health-related quality of life were determined.

Results: At baseline, most patients (75\%) had a Global Initiative for Chronic Obstructive Lung Disease (GOLD) stage of III-IV. Peak exercise performance on a cycle ergometer was on average reduced to $43 \pm 29$ Watt, and health-related quality of life was significantly impaired, with a total score on the St George's Respiratory Questionnaire (SGRQ) of 66. Health-care utilization in the year preceding PR was very high. After rehabilitation, all outcome measures improved statistically significantly $(P<0.001)$. Exercise performance measured with the 6 minute walking distance test improved clinically significantly in $68 \%$ of the patients, whereas $75 \%$ of the patients showed a clinically meaningful improvement in quality of life as measured with the SGRQ. Multiple regression analysis revealed that $19 \%$ of the variation in responses on the 6 minute walking distance test and the SGRQ could be explained on the basis of baseline characteristics.

Conclusion: The present study provides data to indicate that COPD patients may substantially benefit from rehabilitation in a tertiary pulmonary rehabilitation center, despite a severely impaired health status and high level of health-care utilization, in which prior treatment in primary and secondary care have failed to improve health status. Individual rehabilitation responses can only partially be predicted on the basis of baseline characteristics. Consequently, no firm conclusions can be drawn from this study with respect to the selection of candidates that could be deemed eligible for this rehabilitation program when entering the program.

Keywords: BODE index, 6MWDT, HRQL, SGRQ, pulmonary rehabilitation

\section{Introduction}

Chronic obstructive pulmonary disease (COPD) is clinically characterized by breathlessness on exertion and exercise intolerance, both of which not only interfere with the ability to perform the activities of daily life $^{1}$ but also significantly impede quality of life. ${ }^{2}$ Treatment of COPD has focused traditionally on pharmacological improvement of the airway obstruction. Growing evidence of extrapulmonary manifestations in patients with COPD and their consequences for the functioning
Correspondence: Dirk van Ranst Revant, Brabantlaan I, 4817 JW Breda, The Netherlands

$\mathrm{Tel}+3 \mathrm{I} 765797803$

Fax +31 765 331 790

Email d.vanranst@revant.nl 
of these patients has accelerated the development and use of non-pharmacological interventions like pulmonary rehabilitation (PR). PR has been shown now to be the most effective non-pharmacological intervention to improve health status in COPD patients. ${ }^{3}$ The efficacy of PR in improving symptoms, exercise tolerance, and health-related quality of life (HRQL) has been demonstrated by meta-analyses ${ }^{4.5}$ and is recommended in several influential guidelines. ${ }^{6,7}$

In The Netherlands, PR is offered to patients with COPD in a continuum of care, with care being given in private physiotherapy practices, in outpatient clinics of hospitals, and in specialized, tertiary referral centers, formerly tuberculosis sanatoria. In the latter, patients receive a comprehensive rehabilitation program on either an inpatient or outpatient basis by an interdisciplinary team of healthcare professionals. Because of the "last resort function" of these tertiary referral centers, it has become current practice to refer patients with a severely impaired health status. ${ }^{8}$ In many patients, prior treatment, including primary care and hospital-based rehabilitation, had failed to improve health status to a satisfactory level, resulting in a persistently high level of care utilization. These complex patients are often excluded from randomized controlled clinical trials (RCTs). Therefore, research findings may not be applicable to these severely impaired COPD patients. ${ }^{9}$ In support of this concern, a recent review by Bjoernshave et al (2010) concluded that most research evaluating the effects of PR did not include study populations that are sufficiently representative of the COPD target population. ${ }^{10}$

The objectives of the present study were threefold: (1) to evaluate the impact of the disease on different dimensions of health status including health-care utilization in patients with COPD receiving PR in our tertiary referral center; (2) to compare health status measurements prior to and after completion of an intensive, comprehensive interdisciplinary rehabilitation program; and (3) to explore determinants that might predict change in health status following this rehabilitation program.

\section{Materials and methods \\ Patients}

All patients with COPD who participated in the comprehensive program of "Schoondonck" Center for Pulmonary Rehabilitation, Breda, The Netherlands between June 2006 and June 2010 were included in this study. Patients were referred by pulmonologists from the southwest region of The Netherlands to this tertiary referral center for PR. Reasons for referral were a high impact of the disease on health status, with no satisfactory response to prior medical and non-medical treatment, including rehabilitation in primary care and hospital-based rehabilitation. The patients who were referred and enrolled typically had at least three of the following features: (1) severe to very severe airway obstruction (Global Initiative for Chronic Obstructive Lung Disease [GOLD] stage of III-IV); (2) a markedly limited exercise performance with a maximal power output on a cycle ergometer $\left(\mathrm{W}_{\max }\right)$ of less than $50 \%$ predicted; (3) a severely impaired quality of life defined as a St George's Respiratory Questionnaire (SGRQ) total score of more than 50, and, (4) a relatively high annual, selfreported, exacerbation rate (more than three in the preceding year) and markedly high health-care utilization (more than two pulmonary disease-related hospitalizations in the preceding year). Having stopped smoking completely by the start of the program was a prerequisite to participation. Contraindications for participation in the program included severe cognitive disorders resulting in the inability to learn, personality disorders that might interfere with participation in a group program, active psychiatric disorders, inability to communicate, and unstable cardiac or musculoskeletal disease that might interfere with exercise training. Persistent smoking, drug abuse, or legal procedures related to health and potentially interfering with the goals of rehabilitation were also considered to be contraindications.

\section{Study design}

The study was a retrospective, observational study of patients enrolled in a comprehensive PR in a tertiary referral center in The Netherlands. The study was institutional review board exempt because all procedures and measurements were part of the usual care provided in our institute, and due to the use of de-identified, pre-existing data.

\section{The pulmonary rehabilitation program}

\section{Pre-rehabilitation assessment}

A multidisciplinary assessment is an integral part of the PR program. The aim of this assessment is to determine if intensive, comprehensive PR in our tertiary care center is indicated. The indication is based on an evaluation of the impact of the chronic respiratory disorder on different dimensions of health status, that is, physiological functioning, symptoms, activities, quality of life, and health-care utilization. ${ }^{11}$ Moreover, the motivation, commitment, and suitability for participation in an intensive rehabilitation program are evaluated. Finally, individual rehabilitation objectives are set out during the assessment. 
All assessment components are carried out during a 5 day period by a multidisciplinary team consisting of an art therapist, dietician, exercise therapist, physiotherapist, psychologist, pulmonary technician, pulmonary physician, respiratory nurse, occupational therapist, and social worker. The International Classification of Functioning serves as a framework for the assessment which usually takes place 3-4 weeks prior to the interventional phase of the program. ${ }^{12}$ The measurement instruments are consistent with markers that have previously been identified as appropriate for measuring clinically relevant outcomes in COPD. ${ }^{13}$

Pulmonary function parameters were obtained by measuring spirometry, static lung volumes (body box), and single-breath carbon monoxide diffusion capacity (Masterlab, Jaeger, Würzburg, Germany) according to the American Thoracic Society and the European Respiratory Society guidelines, and were related to reference equations produced by the European Community of Coal and Steel. ${ }^{14-17}$ An incremental exercise test was performed to evaluate maximal power output $\left(\mathrm{W}_{\text {max }}\right)$ and peak oxygen uptake $\left(\mathrm{VO} 2_{\text {peak }}\right)$ (Oxycon Pro ${ }^{\mathrm{TM}}$, Jaeger, Würzburg, Germany), according to the European Respiratory Society recommendations on the use of exercise testing in clinical practice. ${ }^{18}$ Blood gases were obtained from capillary blood samples drawn from the earlobe at rest, at the end of the reference phase, at 3 minute intervals during exercise, at peak exercise, and after 3 and 6 minutes of recovery. Medical Research Council (MRC) scores for dyspnea were recorded and the body-mass index, airflow obstruction, dyspnea, and exercise capacity (BODE) index was calculated. ${ }^{19,20}$ Exacerbation type and frequency in the year preceding participation in the rehabilitation were recorded. An exacerbation was defined as an increase in or new onset of more than one symptom of COPD (cough, sputum, wheezing, dyspnea, or chest tightness), with at least one symptom lasting 3 days or more and leading the patient's doctor to initiate treatment with systemic glucocorticoids, antibiotics, or both.

\section{Interdisciplinary rehabilitation}

The program was carried out in a fixed group of eight to ten patients in concordance with the recommendations of current international guidelines on PR, and carried out by the same disciplines as those involved in the assessment. ${ }^{6}$ One week before the program started, patients attended a 2 hour group session in which they had their first face-toface contact with each other and with the case manager, that is, a therapist or nurse acting as the first contact person of the interdisciplinary team. This session served to provide a further exploration of the concept of rehabilitation, that is, the promotion of physical functioning as well as better adaptation to the chronic illness. Patients participated in the program 5 days per week, for a weekly average of 20-25 hours on either an inpatient or outpatient basis. Inpatient rehabilitation was indicated if (1) the travel distance to the center was prohibitive in light of the severity of disability; (2) a temporary removal from the social system was indicated in order to facilitate rehabilitation results, or (3) symptom evaluation required 24 hour observation. All of the program components are shown in the Appendix. Patients received interventions on an individual basis in addition to the group sessions, for example, counseling by a psychologist or social worker, art therapy sessions, or educational conversations with a dietician or respiratory nurse. The health-care professionals determined the indications for individual therapy sessions during the assessment week.

\section{Outcome measurements}

\section{Peripheral muscle performance}

Maximal isometric muscle force of the knee extensors of the dominant leg was measured using a handheld dynamometer (MicroFET2 ${ }^{\mathrm{TM}}$, Biometrics, Almere, The Netherlands). Reference values for healthy elderly subjects established by Andrews et al were used. ${ }^{21}$

\section{Respiratory muscle performance}

Maximal inspiratory mouth pressure $\left(\mathrm{PI}_{\max }\right)$ at residual volume was measured using a handheld respiratory pressure meter (MicroRPM, Micro Medical Ltd, Rochester, UK). The highest of at least five maneuvers was used. ${ }^{22}$ Reference values of Black and Hyatt were deemed the most appropriate for our laboratory. ${ }^{23}$

\section{Exercise performance}

Cycle exercise endurance was determined with a constant work-rate test on a cycle ergometer (Ergoselect 1000, Ergoline, Bitz, Germany) at a work rate equal to $75 \%$ of $\mathrm{W}_{\max }$ obtained in a preceding incremental test. This test has both good reliability and validity. ${ }^{24}$ An improvement of 100-200 seconds in cycle endurance has recently been suggested as the minimal clinically important difference (MCID). ${ }^{25}$

The 6 minute walking distance test (6MWDT) measured in a 40 meter corridor in accordance with the American Thoracic Society guidelines. ${ }^{26}$ At baseline, three tests were performed on alternate days. The results of the third test were used in the analysis. The reference values of Troosters et al 
were used. ${ }^{27} \mathrm{~A}$ difference of 26 meters has been proposed to represent the MCID on this test. ${ }^{28}$

\section{Quality of life}

The Chronic Respiratory disease questionnaire (CRQ) is a 20-item semi-structured interview that measures HRQL in four domains: dyspnea (five items), fatigue (four items), emotions (seven items), and mastery (four items). In addition, a total score can be calculated. ${ }^{29}$ The five questions comprising the dyspnea domain are unique to the respondent. For these, the patient must identify five activities that they undertook frequently and that had produced dyspnea in the past 2 weeks. Each of the five chosen activities is then scored using a 7-point Likert scale; from 1 (extremely short of breath) to 7 (not at all short of breath). The remaining 15 questions encompassing the three other domains are also scored using a 7-point scoring system. Higher scores indicate less impairment in HRQL. A change of 0.5 unit per question resulting from an intervention is considered to be clinically meaningful. ${ }^{30}$

The St George's Respiratory Questionnaire (SGRQ) is a 76-item disease-specific questionnaire. It measures HRQL in three domains: symptoms (distress due to respiratory symptoms), activities (the effects due to impairment of mobility or physical activity), and impacts (the psychosocial impact of the disease), plus a summary total score. ${ }^{31}$ Each item is weighted using empirically derived weights. In addition, a summary score can be calculated. Scores range from 0 (no impairment) to 100 (maximal impairment) for each subscale and for the total score. Lower scores indicate better health status, and a change of 4 points in total score (out of 100) is considered clinically meaningful. ${ }^{32}$

The Medical Outcomes Study Short-Form Survey, version 2 (SF-36) is a 36-item generic health status questionnaire that evaluates eight health concepts: physical functioning (ten items), role functioning: physical (four items), bodily pain (two items), general health (five items), vitality (four items), social functioning (two items), role functioning: emotional (three items), and mental health (five items). Scores were transformed linearly to scales of 0 to 100 , with 0 and 100 assigned to the lowest and highest possible scores, respectively, for all measures of these nine health components. Higher scores indicate better quality of life. Recently, two summary scores have been introduced to improve the interpretation of the SF-36, that is, the physical component score and the mental component score. These scores are standardized to have a mean of 50 and a standard deviation of 10 in normal populations. ${ }^{33}$ The use of the SF-36 has been validated in COPD. ${ }^{34}$ Suggested MCID levels (small, moderate and large) for the change over time, established by three expert panels of physicians are provided on the 8 scales of the SF-36. ${ }^{35}$ Another study suggested that a change of 5 points in the vitality component represents an MCID in this domain. ${ }^{36}$

\section{Statistical analysis}

Differences in characteristics between patients who completed the program and those who dropped out were tested with an independent sample $t$-test for continuous data and with Chisquare for categorical data. $P$-values $<0.05$ were considered to be statistically significant. Measurements before and after completing the program were compared with a paired sample $t$-test. To explore determinants of the change $(\Delta)$ in health status, univariate correlations were first calculated between predictor variables and $\triangle 6 \mathrm{MWDT}$ and $\triangle \mathrm{SGRQ}$. Independent variables that correlated with $\Delta$ health status at the $P<0.05$ level were included in subsequent multivariate analyses. In addition, binary logistic regression analysis (likelihood-ratio change) was performed to identify predictors of responders. For this analysis, the 6MWDT and SGRQ were chosen because they represent two important domains of outcome, that is, exercise performance and quality of life. Moreover, these outcome measures have established levels of MCID. Patients with a response exceeding the MCID were marked as responders, whereas patients with a response lower than the MCID were judged non-responders. The Statistical Package for the Social Sciences (SPSS; SPSS Inc. Chicago, Illinois version 18.0) was used for all statistical tests.

\section{Results \\ Patient characteristics}

Between June 2006 and June 2010, 437 patients with COPD entered the program; 307 inpatients and 130 outpatients. During the course of the program, 48 patients dropped out (11\%). Twenty-one patients dropped out because of medical reasons other than COPD, with hospitalization in four of these patients. Another 13 patients dropped out because of COPD exacerbations, with hospitalization in 11 of these 13 patients. Eleven patients prematurely ended the rehabilitation program due to non-adherence. Two patients died during the program because of non-COPD-related causes. Slightly more patients in the dropout group were inpatients (79\% vs $69 \%$ ). This difference was not significant. Baseline characteristics of the completers and dropouts are presented in Table 1. Dropouts had significantly higher MRC dyspnea scores, a higher resting arterial carbon dioxide tension, poorer exercise performance, and a higher BODE index. Significantly more 
Table I Baseline characteristics of the completers and dropouts on the pulmonary rehabilitation program

\begin{tabular}{|c|c|c|c|}
\hline & Completers $(n=389)$ & Dropouts $(n=48)$ & $P$-value \\
\hline Age, years & $61 \pm 9$ & $63 \pm 9$ & ns \\
\hline Gender, male:female & $205: 184$ & $26: 22$ & ns \\
\hline MRC & $3.6 \pm 0.9$ & $4.0 \pm 1.0$ & $<0.05$ \\
\hline BMI & $26.1 \pm 5.6$ & $25.6 \pm 6.5$ & ns \\
\hline $\mathrm{HbCO}$ & $1.6 \pm 1.1$ & $2.2 \pm 1.6$ & $<0.05$ \\
\hline BODE index & $4.6 \pm 2.0$ & $5.4 \pm 2.1$ & $<0.05$ \\
\hline$\%$ users of chronic oxygen & $17 \%$ & $42 \%$ & $<0.001$ \\
\hline \# exacerbations & $5.2 \pm 4.7$ & $5.2 \pm 3.2$ & ns \\
\hline \# hospitalization & $1.7 \pm 2.4$ & $2.3 \pm 2.5$ & ns \\
\hline \multicolumn{4}{|l|}{ Pulmonary function } \\
\hline $\mathrm{FEV}_{1}, \mathrm{~L}(\%$ pred) & $1.08 \pm 0.50(4| \pm| 7)$ & $1.08 \pm 0.50(4| \pm| 7)$ & ns \\
\hline IVC, L (\% pred) & $3.268 \pm 0.97(95 \pm 19)$ & $3.1 I \pm 1.00(91 \pm 22)$ & ns \\
\hline Tiffeneau, \% & $34 \pm 12$ & $32 \pm 11$ & ns \\
\hline TLC, L (\% pred) & $7.02 \pm 1.58(122 \pm 19)$ & $7.10 \pm 1.65(121 \pm 21)$ & ns \\
\hline FRC, L. (\% pred) & $4.79 \pm 1.43(156 \pm 40)$ & $4.95 \pm 1.42(160 \pm 43)$ & ns \\
\hline RV, L (\% pred) & $3.77 \pm 1.18(178 \pm 54)$ & $4.00 \pm 1.28(184 \pm 62)$ & ns \\
\hline $\mathrm{DL}_{\mathrm{co}}, \mathrm{mmoL} / \mathrm{min} / \mathrm{kPa}(\%$ pred $)$ & $3.76 \pm 1.52(45 \pm 16)$ & $3.558 \pm 1.60(43 \pm 18)$ & ns \\
\hline $\mathrm{PaO}_{2}$ at rest, $\mathrm{kPa}$ & $8.9 \pm 1.2$ & $8.5 \pm 1.1$ & ns \\
\hline $\mathrm{PaCO}_{2}$ at rest, $\mathrm{kPa}$ & $5.3 \pm 0.8$ & $5.6 \pm 0.9$ & $<0.05$ \\
\hline \multicolumn{4}{|l|}{ Exercise performance } \\
\hline $\mathrm{W}_{\max }$, Watt $(\%$ pred $)$ & $44 \pm 19(33 \pm 19)$ & $35 \pm 24(27 \pm 14)$ & $<0.05$ \\
\hline 6MWDT (\% pred) & $366 \pm 104(57 \pm 15)$ & $321 \pm 102(51 \pm 16)$ & $<0.01$ \\
\hline CWR cycle test & $4.7 \pm 3.2$ & $4.3 \pm 2.5$ & ns \\
\hline \multicolumn{4}{|l|}{ Quality of life } \\
\hline SGRQ total score & $66 \pm 12$ & $67 \pm 12$ & ns \\
\hline SF-36-PCS & $31 \pm 79$ & $31 \pm 6$ & ns \\
\hline SF-36-MCS & $42 \pm 12$ & $42 \pm 12$ & ns \\
\hline
\end{tabular}

Notes: Data are presented as mean \pm SD or $\mathrm{n}(\%)$, unless otherwise indicated.

Abbreviations: MRC, Medical Research Council dyspnea scale; BMI, body mass index, BODE, body-mass index, airflow obstruction, dyspnea, and exercise capacity; $\mathrm{FEV}_{1}$, forced expiratory volume in I second; \% pred, \% predicted; L, liter; IVC, inspiratory vital capacity; TLC, total lung capacity; FRC, functional residual capacity; RV, residual volume; $\mathrm{DL}_{c}$, carbon monoxide transfer factor; $\mathrm{PaO}_{2}$, arterial oxygen tension; $\mathrm{PaCO}_{2}$, arterial carbon dioxide tension; $\mathrm{W}_{\text {max }}$, maximal power output on cycle ergometer; 6MWDT, 6 minute walking distance test; CWR, constant work rate; SGRQ, St George's Respiratory Questionnaire; SF-36-PCS, Summary physical component score on the Medical Outcomes Study Short-Form Survey, version 2 (SF-36); SF-36-MCS, Summary mental component score on the SF-36; ns, non-significant.

patients in the dropout group had an $\mathrm{HbCO}>2.5 \%(P=0.04)$, odds ratio 2.16 [1.02-4.57] or were on chronic oxygen $(P<0.001)$, odds ratio 3.37 [1.80-6.33]. The frequency of moderate to severe exacerbations, requiring treatment with oral corticosteroids and/or antibiotics, in the year preceding participation in the PR, did not differ between both groups. Severe exacerbations requiring hospitalization tended to be higher in patients who dropped out $(2.3 \pm 2.5$ vs $1.7 \pm 2.3)$, but did not reach the level of significance $(P=0.10)$. No significant differences were found in age, body mass index, gender, pulmonary function, or quality of life.

Figure 1 shows some clinical phenotyping characteristics of the completers with respect to severity of airway obstruction, BODE index, MRC dyspnea score, and exacerbation frequency. Of the patients completing the rehabilitation, $76 \%$ have GOLD stages of III or IV, and $92 \%$ have an MRC dyspnea score of $\geq 3$. The average BODE index for the completers is $4.6 \pm 2.0$ with
$47 \%$ in quartile 3 or 4 . Forty-five percent of the completers had had five exacerbations or more in the year preceding PR.

Characteristics of the patients completing the PR with respect to exercise performance are provided in Figure 2. Eight patients $(2 \%)$ were only able to cycle unloaded and not capable of tolerating any load at all, not less than 137 patients $(35 \%)$ had a $\mathrm{W}_{\max }$ between 5 and 25 Watt. The high impact of quality of life is illustrated by an average SGRQ total score of $66 \pm 12$.

\section{Changes in health-status measurements}

Changes in measures of health status after 12 weeks of pulmonary rehabilitation are summarized in Table 2 . All measures of muscle performance, exercise performance, and quality of life improved statistically significantly $(P<0.001)$.

Quadriceps muscle strength and maximal inspiratory pressures improved on average by $21 \%$ and $13 \%$, respectively. 

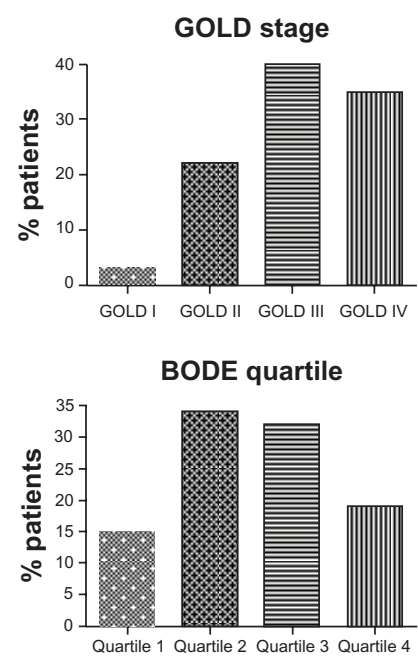

MRC score

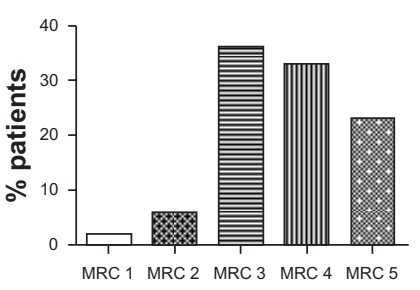

Exacerbations/1 year

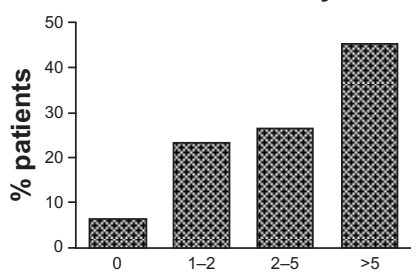

Figure I Baseline clinical phenotyping characteristics of the completers with respect to pulmonary function, dyspnea, BODE index, and exacerbation frequency. Abbreviations: GOLD, Global Initiative for Chronic Obstructive Lung Disease; MRC, Medical Research Council dyspnea scale; BODE, body-mass index, airflow obstruction, dyspnea, and exercise capacity.

With respect to exercise performance, 214 patients $(55 \%)$ were identified as responders on the constant work rate cycle test whereas 265 patients $(68 \%)$ were responders on the 6MWDT. Quality of life measured with the SGRQ showed a clinically meaningful improvement in 290 patients (75\%). The observed changes in SGRQ ranged from a very marked deterioration (an increase of $\geq 12$ points) in eight patients $(2 \%)$ to a very marked improvement (a decrease of $\geq 12$ points) in 206 patients (53\%).

\section{Predictors of improvement in health status}

Significant univariate correlation coefficients were found between $\triangle 6 \mathrm{MWDT}$ and baseline values of forced expiratory volume in 1 second \% predicted (0.24), Tiffeneau (0.28), functional residual capacity $\%$ predicted $(-0.22)$, monoxide transfer factor \% predicted $(0.13)$, quadriceps force $(\mathrm{QF})$ $\%$ predicted $(-0.13)$, maximal ventilation during exercise $\%$ predicted $(-0.13)$, SGRQ total score $(0.15)$, body mass index (0.24), and baseline 6MWDT (-0.23). Furthermore, significant univariate correlation coefficients were found between $\triangle$ SGRQ total score and baseline values of MRC dyspnea score $(0.15$ forced expiratory volume in 1 second $\%$ predicted $(0.10)$, monoxide transfer factor $\%$ predicted $(0.13)$, $\mathrm{W}_{\text {max }}(-0.18), \mathrm{VO}_{\text {peak }}(-0.22), 6 \mathrm{MWDT}(-0.12)$, body mass index (-0.16), and baseline SGRQ total score $(-0.30)$.

Stepwise multiple regression analysis revealed the following independent predictors for $\triangle 6 \mathrm{MWDT}$, baseline
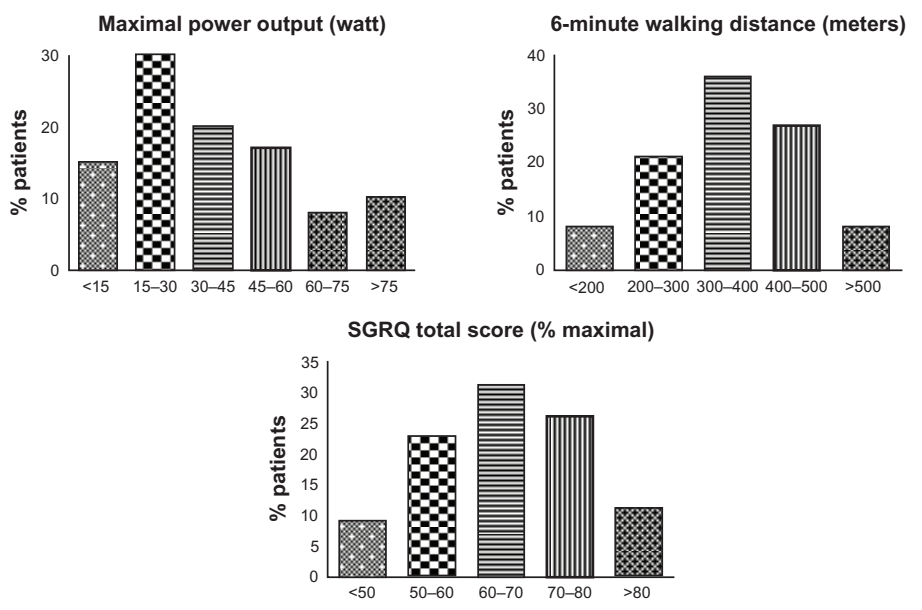

Figure 2 Baseline clinical phenotyping characteristics of the completers with respect to maximal power output on a cycle ergometer, the 6 minute walking distance test, and quality of life.

Abbreviation: SGRQ, St George's Respiratory Questionnaire. 
Table 2 Changes in measures of health status after 12 weeks of pulmonary rehabilitation

\begin{tabular}{|c|c|c|c|c|}
\hline Variable & Pre-PR & Post-PR & $95 \% \mathrm{Cl}$ of the change & $P$-value \\
\hline \multicolumn{5}{|l|}{ Muscle performance } \\
\hline Quadriceps force, $\mathrm{Nm}$ & $262 \pm 99$ & $316 \pm 101$ & $+53[48-58]$ & $<0.001$ \\
\hline $\mathrm{PI}_{\max }, \mathrm{cm} \mathrm{H} \mathrm{H}_{2} \mathrm{O}$ & $72 \pm 24$ & $81 \pm 22$ & $+16[15-18]$ & $<0.001$ \\
\hline \multicolumn{5}{|l|}{ Exercise performance } \\
\hline CWR cycle endurance, seconds & $285 \pm 197$ & $526 \pm 305$ & $+24 \mid[2 \mid 2-27 I]$ & $<0.001$ \\
\hline 6MWDT, meters & $366 \pm 104$ & $418 \pm 107$ & $+52[45-58]$ & $<0.001$ \\
\hline \multicolumn{5}{|l|}{ Quality of life } \\
\hline \multicolumn{5}{|l|}{ CRQ } \\
\hline Dyspnea & $3.2 \pm 0.9$ & $4.9 \pm 1.1$ & $+1.7[1.6-1.8]$ & $<0.001$ \\
\hline Fatigue & $3.4 \pm 1.1$ & $5.0 \pm 1.1$ & $+1.6[1.5-1.7]$ & $<0.001$ \\
\hline Emotions & $4.2 \pm 1.2$ & $5.2 \pm 1.1$ & $+1.1[1.0-1.2]$ & $<0.001$ \\
\hline Mastery & $4.4 \pm 1.4$ & $5.6 \pm 1.1$ & $+1.2[1.1-1.3]$ & $<0.001$ \\
\hline \multicolumn{5}{|l|}{ SGRQ } \\
\hline Symptoms & $65 \pm 19$ & $52 \pm 21$ & $-13[-11-16]$ & $<0.001$ \\
\hline Activities & $83 \pm 11$ & $72 \pm 18$ & $-10[-9-12]$ & $<0.001$ \\
\hline Impact & $56 \pm 15$ & $40 \pm 18$ & $-16[-14-18]$ & $<0.001$ \\
\hline Total & $66 \pm 12$ & $52 \pm 16$ & $-14[-15-18]$ & $<0.001$ \\
\hline \multicolumn{5}{|l|}{ SF-36 } \\
\hline Physical functioning & $23 \pm 18$ & $44 \pm 22$ & $+21[19-23]$ & $<0.001$ \\
\hline Role functioning: physical & $9 \pm 21$ & $35 \pm 36$ & $+26[22-29]$ & $<0.001$ \\
\hline Bodily pain & $63 \pm 27$ & $69 \pm 25$ & $+6[3-9]$ & $<0.001$ \\
\hline General health & $26 \pm 15$ & $35 \pm 18$ & $+9[7-11]$ & $<0.001$ \\
\hline Vitality & $38 \pm 17$ & $57 \pm 18$ & $+19[17-2 \mid]$ & $<0.001$ \\
\hline Social functioning & $48 \pm 26$ & $67 \pm 22$ & $+19[16-22]$ & $<0.001$ \\
\hline Role functioning: emotional & $40 \pm 42$ & $68 \pm 39$ & $+27[22-32]$ & $<0.001$ \\
\hline Mental health & $58 \pm 21$ & $71 \pm 18$ & $+13[11-15]$ & $<0.001$ \\
\hline PCS & $31 \pm 7$ & $36 \pm 9$ & $+5[4-6]$ & $<0.001$ \\
\hline MCS & $42 \pm 12$ & $50 \pm 10$ & $+8[7-9]$ & $<0.001$ \\
\hline
\end{tabular}

Notes: Data are presented as mean \pm SD or $\mathrm{n}(\%)$, unless otherwise indicated.

Abbreviations: $\mathrm{PR}$, pulmonary rehabilitation; $\mathrm{Cl}$, confidence interval; $\mathrm{Nm}$, newton meter; $\mathrm{PI}_{\text {max }}$, maximal inspiratory pressure; CWR, constant work rate; $6 \mathrm{MWDT}$, 6 minute walking distance test; CRQ, Chronic Respiratory Questionnaire; SGRQ, St George's Respiratory Questionnaire; SF-36, Medical Outcomes Study Short-Form Survey, version 2; PCS, summary physical component score on the SF-36; MCS, summary mental component score on the SF-36.

values of: (1) Tiffeneau ( $\mathrm{r}=0.28)$; (2) 6MWDT $(\mathrm{r}=0.38)$; and (3) $\mathrm{VO} 2_{\text {peak }}(\mathrm{r}=0.44)$ in total explaining $19 \%$ of the variance $(\Delta 6 \mathrm{MWDT}=66+0.97 \times$ Tiffeneau $-0.23 \times$ baseline $6 \mathrm{MWDT}+41.2 \times \mathrm{VO} 2_{\text {peak }}$ ). Independent predictors of $\triangle \mathrm{SGRQ}$ total score appeared to be baseline values of: (1) SGRQ ( $\mathrm{r}=0.32)$, (2) $\mathrm{VO} 2_{\text {peak }}(\mathrm{r}=0.41)$, and (3) MRC dyspnea score $(r=0.44)$ in total explaining $19 \%$ of the variance $(\triangle \mathrm{SGRQ}=16-0.48 \times$ baseline $\mathrm{SGRQ}-8.2 \times$ $\mathrm{VO} 2_{\text {peak }}+2.7 \times$ baseline MRC dyspnea score). Stepwise binary logistic regression analysis revealed that baseline 6MWDT was the only significant predictor for $\triangle 6 \mathrm{MWDT}$. By the same method, baseline SGRQ and VO2 $2_{\text {peak }}$ were selected as predictors for $\triangle \mathrm{SGRQ}$.

\section{Discussion}

The main finding of the present study is that statistically significant and clinically relevant improvements were observed in health status after an intensive pulmonary rehabilitation program, in a COPD population with a severely impaired health status either expressed as HRQL or as health-care utilization. Further, a small part of the variance of change in health-status measurements could be predicted on the basis of baseline patient characteristics.

\section{Characteristics of referred patients}

Based on the position of our pulmonary rehabilitation center in the chain of care for people with COPD in The Netherlands, a very significant impact was, as expected, observed of the disease on different aspects of health status, except for pulmonary function impairment. The average severity of the airway obstruction observed in this study $\left(\mathrm{FEV}_{1}=41 \%\right.$ predicted $)$ is in line with the severity reported in many clinical trials on PR, in which typically patients with moderate to severe COPD are included. ${ }^{4}$ A more profound impact was observed on exercise performance and an even greater impact on quality of life. For instance, the SGRQ total score at baseline of 66 
in the present study is 10 points higher than the average of the six studies using the SGRQ in the Cochrane systematic review on pulmonary rehabilitation. ${ }^{4}$

A likely explanation for the high impact on HRQL in the present study is the high number of exacerbations and hospitalizations in the year preceding referral. Health-care utilization and quality of life have been found to be inversely related. ${ }^{37}$ The level of health-care utilization in our population is even higher than that described in a recent study which included COPD patients with chronic hypercapnic failure (5.2 exacerbations/year and 1.7 hospitalizations/year in our population, compared with 3 exacerbations/year and 0-2 hospitalizations/year). ${ }^{38}$

\section{Characteristics of dropouts}

A relatively small portion of the participants (11\%) dropped out during the course of the rehabilitation. In the literature, dropout rates of as high as $31 \%$ have been reported. ${ }^{39}$ One likely explanation for this success was the possibility of offering the program on an inpatient basis to patients with significant exercise intolerance. Difficulties with transportation have been well recognized as a factor interfering with attendance at pulmonary rehabilitation, especially in patients impacted more severely by the disease. ${ }^{40}$ Those who dropped out did so primarily due to medical reasons other than COPD and, secondly, due to COPD exacerbations that require hospitalization. Analysis of the characteristics reveals that these patients were impacted by the disease more severely at entry, as the BODE index was significantly higher. There was greater pulmonary gas exchange disturbance, with a higher arterial carbon dioxide tension at rest. These patients were also more likely to be users of chronic oxygen. Differences in the aforementioned characteristics were present despite similarities in values of spirometry, static lung volumes, and diffusing capacity. The predictive validity of the factors associated with prematurely ending the rehabilitation program, however, is low. Consequently, it is not possible to reliably predict candidates that are likely to complete or vice versa drop out at entry of the program.

\section{Pre- to post-rehabilitation changes in measures of health status}

The pre- to post-rehabilitation changes in all dimensions of health status are significant from both the statistical and clinical points of view. The pre- to post-rehabilitation difference exceeds the MCID by two- to threefold. For instance, the fall in total score of the SGRQ is on average
14 points. This means that the average change in HRQL following our interdisciplinary program is very high. ${ }^{41}$ Further examination of the individual responses shows that $75 \%$ of the completers had a fall in SGRQ total score higher than the MCID of 4 points. This indicates an improvement in HRQL in a vast majority of those who completed the program.

A relevant question to ask now is to what this success can be attributed. By definition PR is a multidisciplinary, individually tailored intervention based on a thorough assessment. ${ }^{6}$ At the start of the program, all patients participated in a 5 day assessment in which important domains potentially determining health status were reviewed. ${ }^{8}$ On the basis of this assessment, a multifaceted, individually tailored program was offered based on individual goals. The patients wrote these goals down in their personal rehabilitation file. One of the members of the rehabilitation team acted as case manager. Every 3 weeks, all patients had an individual session with the case manager to evaluate the progress that had been made in obtaining the individual rehabilitation goals. Diversions from the desired response to the rehabilitation were recognized early, enabling adaptations to the program at an early stage of the rehabilitation. A comprehensive plan of care, including evaluation and revision during rehabilitation, may be considered key elements in maximizing the potential of patients with chronic respiratory conditions. ${ }^{42}$

The intensity of the program is probably another feature that contributes to the results of the program in this seriously affected subgroup of patients, since a "dose-response" relationship has been found for pulmonary rehabilitation. ${ }^{6}$ Our 12-week, 5-days-per-week program is certainly much more intensive than the average program described in RCTs on pulmonary rehabilitation. The "average program" typically has a design of 8-12 weeks, with only three sessions per week of a maximum of 2-3 hours each. Many of the patients participating in our intensive program had failed to improve their health on such a program and were therefore referred to our tertiary center. The majority of these patients benefited from the more intense program that we offered. We also believe that the high level of healthcare utilization in our population might have prevented a less comprehensive rehabilitation program from being successful.

\section{Predictors of success}

In the present study we were also interested in finding predictors of successful outcome of our comprehensive and intense program. Based on accepted MCIDs for the 
6MWDT and SGRQ, we were able to identify responders on exercise performance and HRQL. Responses to rehabilitation turned out to be difficult to predict on the basis of a single set of baseline characteristics or on the basis of a set of multiple independent variables. Explained variances did not exceed $19 \%$. This result complies with earlier studies on the prediction of outcome of PR and suggests that patients impacted most severely by the disease benefit most from our comprehensive rehabilitation. ${ }^{40}$

An explanation for the weak predictability of the response may be the significant heterogeneity of clinical presentation and disease progression in COPD. ${ }^{43}$ Important determinants of symptoms, functional impairment, and quality of life may vary significantly between patients. ${ }^{44}$ Given this variation, it may be well argued that an accurate prediction of individual responses to rehabilitation, on the basis of a single or arbitrary set of baseline characteristics is unlikely. Expectations of an accurate prediction of response to rehabilitation on an individual level may be reduced further, if we realize that PR is an individually tailored intervention, comprised of multiple components. Accurate prediction of response to a variable treatment in a strong heterogeneous target population can hardly be expected. Consequently, the 2001 recommendation from the British Thoracic Society statement on pulmonary rehabilitation is still valid, that is, every patient with persistent symptoms might be considered for pulmonary rehabilitation. ${ }^{45}$

\section{Limitations of this study}

It is known that comorbidities frequently accompany COPD and interfere with health status. ${ }^{46}$ This is also true for many of the patients referred to our center. However, we have not registered the number and/or type of comorbidities in our research charts systematically. This may have resulted in an inability to evaluate statistically the impact of comorbidities on health status and the extent to which this may have affected the change in health status following rehabilitation. In a recent study on the efficacy of rehabilitation in COPD, it was found that the effects of PR on the 6MWDT were inversely but weakly related to the presence of osteoporosis. ${ }^{47}$ No association was found between the presence of comorbidities and change in SGRQ. Interestingly, the best predictors of improvement of a particular outcome were also baseline values in this study. These findings suggest that exclusion of patients for PR should not be based on the presence of comorbidities, but rather the indication for and allocation to different types of comprehensive PR programs should be based on the impact of the disease on overall health status. Instruments that evaluate this impact on overall health status have been developed and are currently undergoing validation. ${ }^{11}$

The lack of control group in this study obviously does not allow firm conclusions to be made about the effectiveness of our program. However, the goal of our study was not to add evidence to the literature on the effectiveness of PR. We agree with the authors of the latest Cochrane systematic review on PR that there are already strong arguments that PR is beneficial and that there is no need for additional RCTs. ${ }^{4}$ Our intention was to gain an impression of the acute outcomes of our interdisciplinary program in a population with a severely impaired health status and a very high level of health-care utilization that might prevent a less intense program from being successful.

\section{Conclusions}

In summary, the present study provides data that COPD patients may substantially benefit from rehabilitation in a tertiary pulmonary rehabilitation center, despite a severely impaired health status and high level of healthcare utilization, in which prior treatment in primary and secondary care have failed to improve health status. Individual rehabilitation responses cannot be reliably predicted on the basis of baseline characteristics. Consequently, no firm conclusions can be drawn from this study with respect to the selection of candidates that could be deemed eligible for this rehabilitation program.

\section{Acknowledgments}

We thank Mrs Krys Galama, Unit Manager at Revant Rehabilitation Center, for her valuable contribution to the final editing of the text and her linguistic support.

\section{Disclosure}

The authors declare that they have no conflicts of interest with regard to the publication of this work.

\section{References}

1. Lahaije AJ, van Helvoort HA, Dekhuijzen PN, Heijdra YF. Physiologic limitations during daily life activities in COPD patients. Respir Med. 2010;104(8):1152-1159.

2. Reardon JZ, Lareau SC, Zuwallack R. Functional status and quality of life in chronic obstructive pulmonary disease. Am J Med. 2006;119 (10 Suppl 1):32-37.

3. Man WD, Kemp P, Moxham J, Polkey MI. Exercise and muscle dysfunction in COPD: implications for pulmonary rehabilitation. Clin Sci (Lond). 2009;117(8):281-291.

4. Lacasse Y, Goldstein R, Lasserson TJ, Martin S. Pulmonary rehabilitation for chronic obstructive pulmonary disease. Cochrane Database Syst Rev. 2006;(4):CD003793. 
5. Langer D, Hendriks E, Burtin C, et al. A clinical practice guideline for physiotherapists treating patients with chronic obstructive pulmonary disease based on a systematic review of available evidence. Clin Rehabil. 2009;23(5):445-462.

6. Nici L, Donner C, Wouters E, et al. American Thoracic Society/European Respiratory Society statement on pulmonary rehabilitation. Am J Respir Crit Care Med. 2006;173(12):1390-1413.

7. Ries AL, Bauldoff GS, Carlin BW, et al. Pulmonary Rehabilitation: Joint ACCP/AACVPR Evidence-Based Clinical Practice Guidelines. Chest. 2007;131(Suppl 5):4S-42S.

8. Peters JB, Daudey L, Heijdra YF, Molema J, Dekhuijzen PN, Vercoulen JH. Development of a battery of instruments for detailed measurement of health status in patients with COPD in routine care: the Nijmegen Clinical Screening Instrument. Qual Life Res. 2009;18(7):901-912.

9. Rothwell PM. External validity of randomised controlled trials: "to whom do the results of this trial apply?" Lancet. 2005;365(9453):82-93.

10. Bjoernshave B, Korsgaard J, Nielsen CV. Does pulmonary rehabilitation work in clinical practice? A review on selection and dropout in randomized controlled trials on pulmonary rehabilitation. Clin Epidemiol. 2010;2: $73-83$.

11. Vercoulen JH, Daudey L, Molema J, et al. An Integral assessment framework of health status in chronic obstructive pulmonary disease (COPD). Int J Behav Med. 2008;15(4):263-279.

12. Stucki A, Stoll T, Cieza A, et al. ICF Core Sets for obstructive pulmonary diseases. J Rehabil Med. 2004;(Suppl 44):114-120.

13. Glaab T, Vogelmeier C, Buhl R. Outcome measures in chronic obstructive pulmonary disease (COPD): strengths and limitations. Respir Res. 2010;11:79

14. Miller MR, Hankinson J, Brusasco V, et al. Standardisation of spirometry. Eur Respir J. 2005;26(2):319-338.

15. Wanger J, Clausen JL, Coates A, et al. Standardisation of the measurement of lung volumes. Eur Respir J. 2005;26(3):511-522.

16. MacIntyre N, Crapo RO, Viegi G, et al. Standardisation of the singlebreath determination of carbon monoxide uptake in the lung. Eur RespirJ. 2005;26(4):720-735.

17. Quanjer PH, Tammeling GJ, Cotes JE, Pedersen OF, Peslin R, Yernault JC. Lung volumes and forced ventilatory flows. Report Working Party Standardization of Lung Function Tests, European Community for Steel and Coal. Official Statement of the European Respiratory Society. Eur Respir J Suppl. 1993;16:5-40.

18. Palange $\mathrm{P}$, Ward SA, Carlsen $\mathrm{KH}$, et al. Recommendations on the use of exercise testing in clinical practice. Eur Respir J. 2007;29(1): 185-209.

19. Bestall JC, Paul EA, Garrod R, et al. Usefulness of the Medical Research Council (MRC) dyspnoea scale as a measure of disability in patients with chronic obstructive pulmonary disease. Thorax. 1999;54:581-586.

20. Celli BR, Cote CG, Marin JM, et al. The body-mass index, airflow obstruction, dyspnea, and exercise capacity index in chronic obstructive pulmonary disease. N Engl J Med. 2004;350(10):1005-1012.

21. Andrews AW, Thomas MW, Bohannon RW. Normative values for isometric muscle force measurements obtained with hand-held dynamometers. Phys Ther. 1996;76(3):248-259.

22. ATS/ERS Statement on respiratory muscle testing. Am J Respir Crit Care Med. 2002;166(4):518-624.

23. Black LF, Hyatt RE. Maximal respiratory pressures: normal values and relationship to age and sex. Am Rev Respir Dis. 1969;99(5): 696-702.

24. O'Donnell DE, Travers J, Webb KA, et al. Reliability of ventilatory parameters during cycle ergometry in multicentre trials in COPD. Eur Respir J. 2009;34(4):866-874.

25. Laviolette L, Bourbeau J, Bernard S, et al. Assessing the impact of pulmonary rehabilitation on functional status in COPD. Thorax. 2008; 63(2):115-121.

26. ATS Committee on Proficiency Standards for Clinical Pulmonary Function Laboratories. ATS statement: guidelines for the six-minute walk test. Am J Respir Crit Care Med. 2002;166(1):111-117.
27. Troosters T, Gosselink R, Decramer M. Six minute walking distance in healthy elderly subjects. Eur Respir J. 1999;14(2):270-274.

28. Puhan MA, Chandra D, Mosenifar Z, et al. National Emphysema Treatment Trial (NETT) Research Group. The minimal important difference of exercise tests in severe COPD. Eur Respir J. 2011; 37(4):784-790. Epub August 6, 2010

29. Guyatt GH, Berman LB, Townsend M, Pugsley SO, Chambers, LW. A measure of quality of life for clinical trials in chronic lung disease. Thorax. 1987;42(10):773-778.

30. Jaeschke R, Singer J, Guyatt GH. Measurement of health status. Ascertaining the minimal clinically important difference. Controlled Clinical Trials. 1989;10(4):407-415.

31. Jones PW, Quirk FH, Baveystock CM, Littlejohns P. A self-complete measure of health status for chronic airflow limitation. The $\mathrm{St}$ George's Respiratory Questionnaire. Am Rev Respir Dis. 1992;145(6): 1321-1327.

32. Jones PW. Interpreting thresholds for a clinically significant change in health status in asthma and COPD. Eur Respir J. 2002;19(3): 398-404.

33. Ware JE, Kosinski M, Keller ASD. SF-36 Physical and Mental Health Summary Scales: A user's Manual; 1994.

34. Mahler DA, Mackowiak JI. Evaluation of the short-form 36-item questionnaire to measure health-related quality of life in patients with COPD. Chest. 1995;107(6):1585-1589.

35. Wyrwich KW, Tierney WM, Babu AN, Kroenke K, Wolinsky FD. A comparison of clinically important differences in health-related quality of life for patients with chronic lung disease, asthma, or heart disease. Health Serv Res. 2005;40(2):577-591.

36. Bjorner JB, Wallenstein GV, Martin MC, et al. Interpreting score differences in the SF-36 Vitality scale: using clinical conditions and functional outcomes to define the minimally important difference. Curr Med Res Opin. 2007;23(4):731-739.

37. Seemungal TA, Donaldson GC, Paul EA, Bestall JC, Jeffries DJ, Wedzicha JA. Effect of exacerbation on quality of life in patients with chronic obstructive pulmonary disease. Am J Respir Crit Care Med. 1998;157(5 Pt 1):1418-1422.

38. Duiverman ML, Wempe JB, Bladder G, et al. Two-year home-based nocturnal noninvasive ventilation added to rehabilitation in chronic obstructive pulmonary disease patients: a randomized controlled trial. Respir Res. 2011;12(1):112.

39. Yohannes AM, Connolly MJ. Pulmonary rehabilitation programmes in the UK: a national representative survey. Clin Rehabil. 2004;18(4): 444-449.

40. Garrod R, Marshall J, Barley E, Jones PW. Predictors of success and failure in pulmonary rehabilitation. Eur Respir J. 2006;27(4): 788-794.

41. Schunemann HJ, Griffith L, Jaeschke R, Goldstein R, Stubbing D, Guyatt GH. Evaluation of the minimal important difference for the feeling thermometer and the St George's Respiratory Questionnaire in patients with chronic airflow obstruction. J Clin Epidemiol. 2003; 56(12):1170-1176.

42. Kuzma AM, Meli Y, Meldrum C, et al. Multidisciplinary care of the patient with chronic obstructive pulmonary disease. Proc Am Thorac Soc. 2008;5(4):567-571.

43. Han MK, Agusti A, Calverley PM, et al. Chronic obstructive pulmonary disease phenotypes: the future of COPD. Am J Respir Crit Care Med. 2010;182(5):598-604.

44. Huijsmans RJ, de Haan A, ten Hacken NN, Straver RV, van 't Hul AJ. The clinical utility of the GOLD classification of COPD disease severity in pulmonary rehabilitation. Respir Med. 2008;102(1):162-171.

45. British Thoracic Society Standards of Care Subcommittee on Pulmonary Rehabilitation. Pulmonary rehabilitation. Thorax. 2001;56(11): 827-834.

46. Cote CG, Dordelly LJ, Celli BR. Impact of COPD exacerbations on patient-centered outcomes. Chest. 2007;131(3):696-704.

47. Crisafulli E, Gorgone P, Vagaggini B, et al. Efficacy of standard rehabilitation in COPD outpatients with comorbidities. Eur Respir J. 2010;36(5):1042-1048. 


\section{Appendix}

\section{Content of the comprehensive pulmonary rehabilitation program \\ I Group modules \\ Physical fitness}

- General exercise reconditioning; three classes per week, $3 / 4$ hour each

- Peripheral muscle training; three classes per week, $3 / 4$ hour each

- Interactive educational class on the importance of an active lifestyle; one class of 1 hour

Physical activity in daily life

- Training in self-management with respect to improving physical behavior; four classes per week, 1 hour each

- Swimming; one class per week, $3 / 4$ hour each

Nutrition

- Interactive educational session on the importance of a healthy diet; one class of 1 hour

Dyspnea management

- Training in relaxation techniques; one class per week, 1 hour each

- Training in body awareness; one class per week, 1 hour each

- Training in breathing retraining at rest and during different types of exercise; one class per week, 1 hour each

- Interactive educational classes on exercise limiting factors; two classes, 1 hour each

\section{Exacerbation management}

- Interactive educational session on exacerbations of chronic obstructive pulmonary disease; one class of 1 hour

- Educational conversations with respiratory nurse on self-management of exacerbations of chronic obstructive pulmonary disease; three sessions, $1 / 2$ hour each

Functional training

- Training in general principles of energy conservation, work simplification strategies, activity configuration for planning daily activities, exploration of avocations, hobby or other meaningful leisure activities, and assessment of adaptations needed to allow patient to continue to participate; two classes per week, 1 hour each

International Journal of COPD

\section{Publish your work in this journal}

The International Journal of COPD is an international, peer-reviewed journal of therapeutics and pharmacology focusing on concise rapid reporting of clinical studies and reviews in COPD. Special focus is given to the pathophysiological processes underlying the disease, intervention programs, patient focused education, and self management protocols.

\section{Medication}

- Consults with a pulmonologist, once per week, $1 / 4$ hour each. Extra visits on indication

- Interactive educational class on medication management; one class of 1 hour

- Interactive educational class on medication inhalation technique; one class of 1 hour

\section{Social system}

- Pre-rehabilitation educational class on the concept of rehabilitation. In this session one or two close relatives are invited to participate; one class of 2 hours

- Interactive educational class on the interaction between a person with a chronic disease and his/her social system. In this session one or two close relatives are invited to participate; one class of 1 hour

- Participation of partner or other close relative on one representative day

\section{Coping}

- Consult with case manager on the progress with regards to individual rehabilitation goals; four sessions, $1 / 2$ hour each

- Interactive educational class on the influence of psychological factors on symptoms, disability, and quality of life in people with a chronic lung condition. In this session one or two close relatives are invited to participate; one class of 1 hour

\section{Illness perceptions and cognitions}

- Interactive educational classes on cognitions with respect to behaviors interfering with appropriate adaptation to a chronic lung condition; two classes of 1 hour

- Creative therapy in which illness perceptions and beliefs are explored nonverbally; one class per week of 1 hour

\section{Individual modules}

On indication, additional modules were added to the aforementioned group modules. These modules were provided on an individual basis and include outdoor physical fitness training, counseling by a dietician, inspiratory muscle training, training in mucus evacuation techniques, consults with a respiratory nurse whenever the need was insufficiently met with the group sessions, consults with an occupational therapist, consults with a creative therapist for assistance with hobby development, consults with a psychologist, consults with a social worker.

\section{Dovepress}

This journal is indexed on PubMed Central, MedLine and CAS. The manuscript management system is completely online and includes a very quick and fair peer-review system, which is all easy to use. Visit $\mathrm{http}: / /$ www.dovepress.com/testimonials.php to read real quotes from published authors. 